\title{
O cotidiano do trabalho em cuidados paliativos na percepção dos profissionais de saúde
}

\author{
Teresa Cristina Gioia Schimidt, D.Sc.*, Viviane Soares Rocha do Nascimento**
}

*Enfermeira, Integrante do Núcleo Técnico de Envelhecimento e Saúde da Pessoa Idosa da Secretaria de Estado da Saúde de São Paulo, Docente Colaboradora na Escola de Enfermagem da Universidade de Sáo Paulo no Departamento Médico Cirúrgico, Docente da Universidade Nove de Julho no Departamento de Saúde, São Paulo, **Enfermeira graduada pela Universidade Nove de Julho

\section{Resumo}

O objetivo foi identificar o recebimento de capacitação em cuidados paliativos, bem como conceito de finitude, sentimentos, fatores de interferência e mecanismos de superação e o tipo de relação interpessoal mantida. Pesquisa de campo e transversal com abordagem quali-quantitativa desenvolvida com 20 profissionais de saúde que trabalhavam diretamente com clientes em cuidados paliativos em um hospital filantrópico da capital paulista. Os resultados revelaram que, apesar da maioria não ter capacitação nessa área, foi unânime a afirmativa de sua importância. Consideram a finitude humana uma etapa a ser vivida com dignidade. A dor, angústia, medo e depressão foram as condições mais recordadas no atendimento dos clientes. As interferências cotidianas mais citadas foram a escassez de pessoal, material, tempo, desvalorização profissional e problemas comunicacionais. Os mecanismos de enfrentamento citados estavam ligados à humanização, ética e responsabilidade. A relação entre profissionais e binômio profissional-cliente foi avaliada como boa e favorável ao aprendizado.

Palavras-chave: cuidados paliativos, profissional de saúde, paciente terminal.

\section{Abstract \\ Care providers' perception of everyday work activities in palliative care}

The goal was to identify training in palliative cares, and also feelings, concept of finitude, interference factors, overcoming mechanisms and maintained interpersonal relationship. This was a cross-sectional field work with quali and quantitative approach performed among 20 healthcare providers directly involved in palliative care at a charity hospital in São Paulo/SP. Results showed that although most professionals were never trained in that specific field, they all acknowledged the key role of such an approach. As they deemed human finitude step to be faced with dignity, the subjects in this study pointed out the following conditions while applying palliative treatment: pain, distress, fear and depression. Some of the most commonly cited work interference factors included few staff members, few materials, little time, job depreciation, and communication problems. Among the commonest mechanisms to be coped with were humanization, ethics, and responsibility. The care provider-customer combination was deemed as a positive relationship that encourages learning.

Key-words: hospice care, health personnel, terminal patient. 


\section{Resumen \\ El trabajo cotidiano en cuidados paliativos en la percepción de profesionales de la salud}

El objetivo fue identificar la percepción del cotidiano de los profesionales, incluyendo conceptos de finitud, sentimientos, factores de interferência, mecanismos de superación y la relación interpersonal. Investigación de campo transversal con enfoque cualitativo y cuantitativo desarrollada con 20 profesionales de salud que trabajaron directamente con clientes en cuidados paliativos en un hospital filantrópico de São Paulo/SP. Los resultados revelaron que a pesar de la mayoría no haber hecho el curso en el área, fueron unánimes en afirmar su importancia. Consideran la finitud humana una etapa a ser vivida con dignidad. El dolor, angustia, miedo y depresión fueron las condiciones más recordadas en la atención de clientes en cuidados paliativos. Algunas de las interferencias en el trabajo más citadas fueron la escasez de personal, de material, de tiempo, desvalorización profesional y problemas comunicacionales. Los mecanismos de enfrentamiento recordados estaban relacionados a la humanización, ética y responsabilidad. La relación entre los profesionales y binomio profesional-cliente fue evaluada como buena y favorable al aprendizaje.

Palabras-clave: cuidados paliativos, personal de salud, enfermo terminal.

\section{Introdução}

Apesar de todo o avanço da Medicina existem ocasióes que mesmo com o emprego de todos os recursos existentes, a doença não responde mais ao tratamento médico com eficácia. Não é raro, mesmo que a doença seja considerada como incurável (no sentido de cura ou de alterar a progressão da mesma) ou intratável, o paciente acaba por ser submetido aos mais diversos tratamentos, inclusive fúteis, dolorosos, desnecessários e sem proporcionar qualquer tipo de benefício; ao contrário, com chances de causar maior sofrimento ao paciente tanto no aspecto físico como emocional [1].

O cuidado paliativo deve incluir competências de ajuda com problemas existenciais, tais como o significado do desespero de vida e dignidade da pessoa no final da sua vida [2]. Nos últimos anos observa-se que a equipe multidisciplinar de saúde tem investido muito no campo de cuidados e apoio aos indivíduos considerados fora de condiçôes terapêuticas, tendo como foco central a família e o paciente. Uma das realidades mais difíceis é o enfrentamento da finitude humana, onde se percebe que apesar dos esforços técnicos não se é dono da vida, logo os pacientes morrerão. Embora não se possa alterar esse fato, pode-se agir de maneira significativa e, assim, interferir diretamente no modo pelo qual o paciente encara a vida, a vive e se prepara para o processo de morrer.

O modo pelo qual a morte acontece e as vivências da família em relação a esse momento são peculiares e devem ser motivos de zelo, preocupação e responsabilidade dos profissionais que tratam e cuidam dos mais diversos tipos de pacientes [3]. Estudos revelam que os graduandos têm sido ensinados a lidar com a cura, o cuidado, com a vida, contudo, parece haver certa negligência com a temática morte e morrer, quando ela ocorre é de maneira pontual e pouco sistemática [4].

Sendo assim, é necessário apropriar-se de recursos capazes de aprender a lidar com as perdas independentemente do contexto das doenças sem prognóstico. Este é um desafio que poucos se disponibilizam para discutir e muito menos enfrentar. A assistência aos indivíduos e o auxílio aos seus familiares no processo de terminalidade, inclui um modelo de atenção à saúde que prevê um conjunto de açôes denominadas como cuidados paliativos [5].

O termo paliativo deriva do vocábulo latino, que significa manto ou coberta. Assim, quando a causa náo pode mais ser curada, os sintomas sáo cobertos com tratamento específicos, por exemplo, analgésicos [6]. Sendo assim, o intuito de cuidados paliativos, é aliviar o sintoma e não promover a cura.

Cuidados paliativos também refere-se aos cuidados dos pacientes nos últimos dias, semanas ou meses de vida, quando se torna claro seu estado progressivo de declínio. Esses devem priorizar a qualidade de vida possível e não o prolongamento da vida a qualquer preço [7].

Considera-se neste estudo que cuidados paliativos como a assistência promovida por uma equipe multidisciplinar, que objetiva a melhoria da qualidade de vida do paciente e seus familiares diante de uma doença que ameace a vida por meio da prevenção e alívio do sofrimento, da identificação precoce, avaliaçáo impecável e tratamento da 
dor e demais sintomas físicos, sociais, psicológicos e espirituais [8].

Como já descrito, cuidados paliativos é um conjunto de atos e controles multiprofissionais que tem por objetivo efetuar o controle de sintomas do corpo, da mente, do espírito e do social, que afligem o homem na sua finitude, ou seja, quando a morte dele se aproxima [9]. A filosofia dos cuidados paliativos tem apresentado uma movimentação crescente dentro da equipe multidisciplinar de saúde, bem como um papel diferenciado no contexto assistencial das políticas de saúde e currículos de profissionais da área [10].

Os profissionais que compóem a equipe são os que controlam os sintomas do corpo (médico, enfermeiro, fisioterapeuta, terapeuta ocupacional), da mente (psicólogo, psicoterapeuta, psicoanalista, psiquiatra), do espírito, (padre, pastor, rabino, sacerdotes das diferentes crenças religiosas professadas pelos pacientes, capeláo), do social (assistente social, voluntários). Além desses, na dependência da evolução clínica do caso, outros profissionais e especialistas poderão ser chamados a cooperar com a equipe. Não existe mais o objetivo de curar o paciente, pois a doença está em fase progressiva, irreversível e não responsiva [9].

Todos esses profissionais entram em cena quando, a maioria das vezes o médico dá a notícia que "não há mais nada a fazer", o que acaba por condenar irremediavelmente o paciente ao abandono, a ficar entregue ao seu sofrimento, com ou sem esperança de um milagre [11].

Estudo evidenciou que os profissionais de diferentes áreas tem exercido suas funçôes de maneira isolada, com baixa cooperaçáo ou espírito de trabalho em equipe. O que há é uma limitaçáo em trocar informaçóes por meio de registro em prontuários, e algumas vezes, prevalecendo o sistema de referência ou simples pedido de interconsulta o que não garante integralidade das açóes. Neste âmbito precisa-se compreender que a reciprocidade, a boa comunicação e o trabalho em equipe quando focado em objetivo comum trazem enriquecimento mútuo entre os envolvidos, cria-se uma tendência de horizontalidade nas relaçóes de poder o que pode produzir grande diferença no resultado final ao binômio paciente-profissional [12].

É interessante aqui relacionar alguns objetivos das distintas áreas quando se está em cuidados paliativos: a Fisioterapia, que tem como objetivo preservar, desenvolver ou restaurar a integralidade dos órgãos, sistemas e função [13]; a Enfermagem tem como prioridade o processo de cuidar, promovendo o bem estar e conforto ao lado de pessoas com perda da vitalidade, com dor, depressáo, perda $\mathrm{da}$ autonomia, entre outros sintomas e sinais tentando conhecer e respeitar seus valores espirituais e culturais, criando oportunidade para que resolvam assuntos pendentes principalmente com a família, e funcionando como um elo de ajuda na relaçáo com os médicos por estar mais horas do dia junto ao paciente; o Serviço Social e a Psicologia náo são restritos somente ao paciente, devem se estender também a família como parte indivisível da unidade de cuidado [14].

Defende-se o pressuposto que o trabalho quando realizado em equipe potencializa os recursos existentes e favorece o cuidado efetivo ao paciente. Propiciar a assistência paliativa, vai além de considerá-la alternativa, náo devendo ser estabelecida com o foco de cuidar devido à ineficácia do tratamento curativo, mas sim deve reunir um conjunto de cuidados prestados ao paciente desde o início da sua terapêutica, configurando, assim, uma abordagem especializada para ajudar a pessoa a viver melhor, favorecendo todo e qualquer tratamento que promova sua qualidade de vida até mesmo quando se está em processo de morte e morrer [15].

\section{Objetivos}

- Verificar se os profissionais foram ou não submetidos algum tipo de treinamento e instrução para trabalhar em cuidados paliativos;

- Descrever a compreensão dos profissionais frente aos cuidados paliativos bem como se sentem em trabalhar nessa área;

- Discutir o conceito atribuído frente à finitude humana;

- Relacionar os sentimentos observados, pelos profissionais, dos pacientes que estão em cuidados paliativos;

- Identificar os fatores que interferem na realização efetiva e de qualidade do trabalho no cotidiano dos profissionais que exercem suas atividades em cuidado paliativo;

- Citar os mecanismos e/ou características que os profissionais utilizam para trabalhar com o paciente sob cuidado paliativo;

- Verificar o tipo de relaçáo que os profissionais mantem entre os colegas da equipe, pacientes e seus familiares. 
Material e métodos

Pesquisa de campo e transversal com abordagem quali-quantitativa desenvolvida num hospital filantrópico da capital paulista. Os sujeitos da pesquisa foram 20 profissionais de saúde (representando $40 \%$ do total existente) desde que tivessem experiência mínima de seis meses exercendo suas funçôes trabalhistas direta ou indireta junto aos clientes em cuidados paliativos que estivessem internados na unidade de clínica médica. Pesquisa foi iniciada no $2^{\circ}$ semestre/2011, somente após aprovação do Comitê de Ética em Pesquisa com Seres Humanos (Parecer COEP no47/2011), mediante concordância e assinatura do Termo de Consentimento Livre e Esclarecido e após ter sido assegurada pela pesquisadora o total sigilo e privacidade dos voluntários quanto aos dados envolvidos na mesma.

Utilizou-se questionário composto de onze questóes fechadas capazes de traçar o perfil dos participantes e de responder aos objetivos da pesquisa. Como forma de garantir o anonimato dos sujeitos, todos os profissionais receberam o questionário em envelope do tipo carta individual não identificado. Eles tiveram um prazo de devoluçáo de três dias, como forma do mesmo preencher sem contudo interferir na sua vontade e também na dinâmica da unidade de internação.

Os envelopes respondidos foram colocados sem qualquer tipo de informe em duas urnas (TCLE e RESPOSTAS) especialmente criadas para esse fim que ficaram expostas na unidade de clínica médica durante o período de coleta de dados.

As respostas dos questionários foram devidamente digitadas em planilha do EXCEL versão 2007 que serviu como banco de dados da pesquisa. Os dados qualitativos foram analisados conforme Minayo [16] e os quantitativos por medida de tendência central.

\section{Resultados e discussão}

A amostra foi constituída de 20 participantes que exerciam suas funçóes profissionais diretamente ligadas ao cliente sob o cuidado paliativo, $85 \%$ de nível superior e $15 \%$ de nível médio, sendo 45\% pertencentes a equipe de enfermagem - $(66,7 \%$ enfermeiros e 33,3\% técnicos de enfermagem); $25 \%$ médicos; $15 \%$ fisioterapeutas ou fonoaudiólogos e os demais $15 \%$ nutricionista, assistente social e psicólogo.
A média de idade foi de 35,6 anos com intervalo que variou de 28 a 50 anos de idade. A experiência profissional foi de 10, 4 anos em média, sendo a menor de 3 e a maior de 25 anos, já a experiência em de trabalhar na área de cuidados paliativos alcançou a média de 4,8 anos, os dados revelaram que $75 \%$ tinham experiência de até 5 anos, $10 \%$ de 6 a 10 anos e $15 \%$ superior a 10 anos.

Quando questionados sobre terem ou não sido submetidos à capacitação específica em cuidados paliativos, a grande maioria $(90 \%)$ responderam não ter sido capacitados, entre esses $50 \%$ afirmaram que se sentem experientes e aptos para atuar na área mesmo sem participar de cursos específicos, 38,9\% encontravam-se em capacitação e 11,1\% referiram desejar serem capacitados

Todos foram unânimes em afirmar que consideram importante e válida a temática sobre cuidados paliativos e desta ser inserida nos currículos de graduação em todos os cursos da área da saúde.

Esta necessidade é reforçada pela grande parte das universidades não oferecer conteúdo para os alunos e quando há, estes escassos cursos abordam a temática de maneira a priorizar as questôes técnicas e negligenciar as habilidades humanitárias, tornando-os um tanto quanto superficiais [17].

O curso proposto pela International Society of Nurses in Cancer Care [18], por exemplo, selecionou dez módulos, a saber: morte, sociedade e cuidados paliativos; experiência do doente e de seus cuidadores; enfermagem em cuidados paliativos; manejo de sintomas 1, manejo de sintomas 2; emergência em cuidados paliativos; comunicação terapêutica; cuidado na últimas horas de vida; perda e luto; e ética no fim da vida.

É importante salientar que o aprendizado referente aos cuidados paliativos deve prever estratégias para a incorporação de crenças e valores, como campaixão, respeito, autonomia, sinceridade e sensibilidade, entre outros, e habilidades, como a comunicação empática [17].

Os resultados em relação aos sentimentos e percepçóes que os profissionais relataram, frente ao trabalho em cuidados paliativos, permitiram a construção de três tipos de agrupamentos: positivos (40\%), que reuniu as respostas que expressaram estritamente pontos postivos e bons traduzidos como uma atividade prazerosa, gratificante, compensadora e/ou que traz aprendizagem; negativos (15\%), englobou as respostas exclusivamente negativas como atividade triste, desgastante, estressante e cansativa, 
e mistos (45\%), aquelas respostas que tinham ambos os sentidos (positivos e negativos).

Quando se utiliza os termos positivo ou negativo para discutir emoçôes e afetos tem-se o objetivo de relacioná-los com a aproximação ou afastamento das outras pessoas, o que acaba por interferir na felicidade humana [19].

A emoção positiva é importante não pela sensação agradável que produz, mas pela possibilidade que ela traz na realização pessoal e até mesmo profissional. Além disso, os sentimentos positivos ajudam a desfazer os efeitos prolongados das emoçóes negativas e produz aprendizado interno [19].

A motivação no universo saúde-doença vivenciada pela equipe de saúde constitui um imenso desafio. Quando observada e refletida a variedade de condiçóes que influenciam o comportamento e a expressão de sentimentos frente ao indivíduo cuidado, ela pode proporcionar uma fonte de conhecimento sobre a condição humana e, consequentemente, o cotidiano ser enfrentado sem que seja negado a presença da tristeza, desgaste e estresse que ronda os profissionais de saúde [20].

Existem trabalhos que mostraram que o nível de estresse dos profissionais de saúde, incluindo médicos residentes, é semelhante daqueles clientes que apresentam quadro de distúrbio pós-traumático consequente a desastres. A equipe pode estar sujeita a diversas causas de estresse, desde as peculiaridades dos tipos de clientes que atendem até a insuficiência de verbas destinadas à saúde o que interfere na qualidade do atendimento [21].

O sofrimento vivenciado pelo cliente oncológico se torna o referencial humano do trabalho da equipe de saúde nas situaçóes que surgem, e as medidas devem ser direcionadas para a contençáo e controle desse sofrimento. A falta de recursos técnicos, em suas mais variadas justificativas, não constitui impedimento para que o recurso humanitário seja exercido em sua totalidade, e a presença gerenciadora do médico tem sido retratada como uma exigência à promoção da assistência em saúde [21].

A finitude humana precisa ser encarada não simplesmente como um evento, mas como um processo que merece ser observado, vivido e respeitado em suas várias dimensóes [22]. Valorizando essa afirmativa, foi perguntado aos participantes qual o conceito que eles atribuíam a finitude do homem. Os resultados encontrados foram que é que a maioria $(70 \%)$ a considerou com etapa da vida ou ciclo da vida completado e $15 \%$ definiram como fim da angústia, dor e descanso e os demais 15\% atribuíram à perda e tristeza como conceito.

A morte abriga em si o mito do fim, mito sobre o qual não há como racionalizar a despeito de inúmeras respostas para a finitude. A realidade é que não é possível destituí-la do mistério que abarca [23]. Pesquisa desenvolvida concluiu que a falta de preparo das equipes de saúde e, em especial, dos médicos, no trato do fenômeno de finitude humana, é fruto de uma formação deficitária no que se refere à relação médico-paciente, somada a um processo social histórico de relegar a morte a um plano quase oculto no mundo contemporâneo [24].

Os avanços da tecnociencia e da medicina trouxeram ganhos, entretanto contribuíram significativamente para a negação desmedida da morte, à medida que passaram nesse âmbito a oferecer ao sujeito a falsa impressão de imortalidade, favorecendo o consequente temor da sua finutude seja por privação da vida ou advinda da possibilidade de sofrimento e dor da morte [23].

Pesquisa realizada com graduandos em enfermagem corrobora estes resultados, pois parte deles atribuíram o significado à morte como ciclo da vida finalizado, fim com passagem para outra vida e término da dor e sofrimento [23].

É essencial referenciar que o cuidado na perspectiva da morte englobam um conjunto de teorias e práticas que tem por objeto central o processo de morrer [22]. Pesquisa realizada por especialistas em cuidados paliativo identificaram seis elementos considerados chaves no cuidar do processo morrer, são eles: qualidade de vida geral, desempenho e bem-estar físico, desempenho e bem-estar psicossocial, desempenho e bem-estar espiritual, percepção do cliente acerca do cuidado e as percepçóes e o bem-estar da família [25].

As percepçóes dos profissionais do cotidiano dos clientes em cuidados paliativos foram averiguadas, sendo a dor verificada que $50 \%$ deles como a ocorrência mais incidente. A angústia e o medo foram relatados como os principais sentimentos para $35 \%$ seguida pela depressão em $10 \%$. Em contrapartida a paz foi para $75 \%$ o sentimento menos exposto e percebido pelos profissionais que assistem esses clientes.

Profissionais médicos investigados numa pesquisa concordaram que os cuidados paliativos aumentam a qualidade de vida do paciente terminal, $70 \%$ deles afirmaram observar um alívio da dor, $60 \%$ melhora na autoestima e 50\% minimização 
da depressão e favorecimento da aceitaçáo do estado de terminalidade [26].

Encarar a morte tem sido assumido como uma atividade difícil a ser desenvolvida pelos profissionais de saúde, o mesmo acontece ao verificar que a necessidade de manter uma relação com o cliente que vai morrer, conversando com ele, examinando-o, respondendo aos seus questionamentos ou aos de sua família. Tudo isso sem dúvida constitui um processo que exige preparo, vontade, intenção e maturidade profissional [24].

Os fatores do cotidiano percebidos pelos profissionais estudados que interferem na realização efetiva e de qualidade do trabalho a ser desenvolvida junto ao cliente foram para $45 \%$, o quantitativo reduzido de recursos humanos, seguido da escassez de recursos materiais (40\%), sentimento de desvalorização profissional (35\%), tempo disponível (30\%); problemas ligados à comunicação seja entre a própria equipe ou entre os cliente e familiares (20\%) e necessidade de maior conhecimento sobre como lidar com cuidados paliativos (5\%). Ressalta-se que o somatório não totaliza $100 \%$, pois o mesmo profissional atribui mais que um fator de interferência na qualidade do trabalho.

A precarização no trabalho, os conflitos, os sentimentos de medo e insegurança, o reduzido tempo, o acúmulo de atividades, as condições materiais, a baixa autoestima, a desvalorização profissional, a sensação de impotência, a competição e a disputa por poder acabam gerando nos profissionais de saúde um alto grau de estresse e de frustração, provocando interferência na qualidade do trabalho desenvolvido [27].

Os três mecanismos operacionais e interacionais que os profissionais mais prevalentes citados como os mais aplicados e importantes para lidar e agir com o cliente sob cuidados paliativos foram na ordem decrescente: humanização; ética e responsabilidade.

Ratificam estes resultados a defesa posta por autores que afirmam que a agir com humanização, ética e responsabilidade são quesitos essenciais ao cuidado humano [28,29]. Quando se exerce os princípios do cuidar expressivo estes promovem o fortalecimento do vínculo e acaba por possibilitar o exercício da autonomia e cidadania do ser cuidado, consequentemente, ampliam a eficácia das ações de saúde e constroem um nova ética, de diversidade e tolerancia aos diferentes, de inclusão social com escuta solidária, humana, afetuosa, responsável, comprometida com o humano [29].
Finalmente, a avaliação realizada pelo tipo de relação estabelecida e mantida dos profissionais investigados com os colegas da equipe foi classificada como muito boa para $75 \%$ e $25 \%$ favorável ao aprendizado, revelando uma percepção positiva. O mesmo ocorreu em relação aos clientes e seus familiares, cuja avaliação foi $50 \%$ muito boa e $50 \%$ favorável, indicando uma satisfação interpessoal.

\section{Conclusão}

Um passo importante para cada profissional dar início ao aprendizado sobre o ato de morrer é aceitar que a consciência humana implica o reconhecimento da finitude da vida como um acontecimento que náo o exclui, mas que o coloca de imediato na possibilidade de compreensão e compartilhamento da morte vivida pelo outro. $\mathrm{O}$ desafio que permanece aos profissionais de saúde é sempre o de aliar competência técnica com o ato de cuidar com ternura pela vida e pela sensibilidade ética, respeitando os desejos e as decisóes do cliente sob sua responsabilidade.

Neste estudo concluiu-se que apesar da grande maioria dos profissionais náo ter sido submetida à capacitaçáo específica em cuidados paliativos, sente-se apta a exercer suas atividades, visto que se utilizam de suas experiências práticas no cotidiano. Foram unânimes no reconhecimento da validade e importância de conteúdos sobre cuidados paliativos serem inserido nos currículos de graduaçáo em todos os cursos da área da saúde.

Os sentimentos e percepçóes que os profissionais relataram, frente ao trabalho em cuidados paliativos foram quantitativamente mais positivas que negativas. $\mathrm{O}$ entendimento sobre finitude humana para a maioria foi considerada como uma etapa da vida ou ciclo da vida completado, seguida pelo fim da angústia, dor e descanso.

A dor, angústia, medo e depressão foram as condiçóes mais recordadas no atendimento de clientes em cuidados paliativos.

O quantitativo reduzido de recursos humanos; seguido da escassez de recursos materiais, sentimento de desvalorização profissional, tempo disponível; problemas ligados à comunicação seja entre a própria equipe ou entre os cliente e familiares, e necessidade de maior conhecimento sobre como lidar com cuidados paliativos foram os fatores que interferem na qualidade e no cotidiano do trabalho dos profissionais estudados. 
Os três mecanismos operacionais e interacionais que os profissionais citaram como os mais aplicados e importantes para lidar e agir com o cliente sob cuidados paliativos foram na ordem decrescente: humanização; ética e responsabilidade.

A relação estabelecida e mantida entre os profissionais e entre o binômio profissional-cliente foi avaliada como boa e favorável ao aprendizado pessoal e profissional.

\section{Referências}

1. Hospital Santa Marcelina. Manual de Cuidados Paliativos: controle dos sintomas. $2^{\mathrm{a}}$ ed. São Paulo: Hospital Santa Marcelina; 2008.

2. Breitbart W. As metas dos cuidados paliativos: além do controle dos sintomas. Palliata Cuidados de Suporte 2006;4(1):1-2.

3. Kruse M, Vieira R, Ambrosini L, Niemeyer F, Pacheco F da. Cuidados Paliativos: uma experiência. Revista HCPA 2007;27(2):49-52.

4. Bellato R, Araujo AP de, Ferreira HF, Rodrigues PF. A abordagem do processo de morrer e da morte feita por docentes em um curso de graduação em Enfermagem. Acta Paul Enferm 2007;20(3):255-63.

5. Silva RF da, Hortale VA. Cuidados paliativos oncológicos: elementos para o debate de diretrizes nesta área. Cad Saúde Pública 2006;22(10):2055-66.

6. Pessini L, Bertachini L. Humanização e cuidados paliativos. O conceito e a filosofia de cuidados paliativos. São Paulo: Loyola; 2004. p.181-186.

7. Brandão C. Câncer e cuidados paliativos: definiçôes. Prática Hospitalar 2005;42(7):54-56.

8. Organização Mundial da Saúde (OMS) Definition of Palliative Care 2002. [citado 2011 Mai 13]. Disponível em URL: http://www.who.int/cancer/palliative/ definition/en/.

9. Taquemori LY, Sera CTN. Cuidado paliativo.Conselho Regional de Medicina do Estado de São Paulo: São Paulo; 2008. p.55-7.

10. Thaller TS, Silva MJP, Possari JF. Identificação das fases do processo de morrer pelos profissionais de Enfermagem. Acta Paul Enferm 2006;19(2):144-9.

11. Figueiredo MT. Educação em cuidados paliativos, uma experiência brasileira. Mundo Saúde 1995;27(1):16570.
12. Campos MA. O trabalho em equipe multiprofissional: Uma reflexão critica. J Bras Psiquiatr 1992;41(6):256-7.

13. Conselho Federal de Fisioterapia e Terapia Ocupacional. Definição e objetivo. [citado 2011 Mai 17]. Disponível em URL: http://www.coffito.org.br

14. Silva MJP, Araujo MT, Firmino F. Cuidado Paliativo. São Paulo: Conselho Regional de Medicina do Estado de São Paulo; 2008. p.58-87.

15. Boemer MR. Sobre cuidados paliativos. Rev Esc Enferm USP 2009;43(3):500-1.

16. Minayo MCS. O desafio do conhecimento: pesquisa qualitativa em saúde. 8a ed. São Paulo: Hucitec; 2004.

17. Pimenta CAM, Mota DDCF. Educaçáo em cuidados paliativos. In: Pimenta CAM, Mota DDCF, Cruz DALM, eds. Dor e cuidados paliativos. São Paulo: Manole; 2006. p.29-44.

18. International society of nurses cancer care (ISNCC). A core curriculum for palliative nursing. Mediate Health Consulting. 2aed. Cheshire UK; 2002.

19. Fredrickson BL. The role of positive emotions in positive psychology: the broaden-and-build theory of positive emotion. Am Psychol 2001;56:218-26.

20. Seligman MEP, Csikszentmihallyi M. Positive psychology: an introduction. Am Psychol 2000;55(1):5-14.

21. Camargo ALLS, Brandt RA. Transtornos factícios: desafio ético. Ed Cont Saúde 2008;6(4):188-90.

22. Martins LAN. Residência médica: estresse e crescimento. São Paulo: Casa do Psicólogo; 2005.

23. Rego S, Palácios M. A finitude humana e a saúde pública. Cad Saúde Pública 2006;22(8):1755-60.

24. Prochet TC. Os sentimentos e os pensamentos sobre a morte e o processo de morrer. Enfermagem Brasil 2009;8(3):131-8.

25. Nogueira ACC, Oliveira CH, Pimentel V. O Profissional da Saúde e a Finitude Humana: a negaçáo da morte no cotidiano profissional da assistência hospitalar. Revista Virtual Textos e Contextos 2006;5(2):1-12.

26. Singer PA, Bowman KW. Quality end-of-life care: a global perspective. BMC Palliat Care 2002;1(4):1-10.

27. Oliveira FT, Flavio DA, Marengo MO, Silva RHA. Bioética e humanização na fase final da vida: visão de médicos. Rev Bioét 2011;19(1):247-58.

28. Araujo MFS, Veras KFO. Processo e precarizaçáo do trabalho no programa de saúde da família. Revista Eletrônica de Ciências Sociais 2009;14:41-56.

29. Waldow VR. Cuidar expressão humanizadora da Enfermagem. 2a ed. Petrópolis: Vozes; 2007.

30. Boff L. Saber cuidar, ética do humano: compaixão pela Terra. 16a ed. Petrópolis: Vozes; 2009. 